\title{
Urgences
}

\section{Octobre : Rock garden}

\section{Claude Beausoleil et Michaël Delisle}

Numéro 16, mars 1987

D.G. Jones : d'un texte, d'autres

URI : https://id.erudit.org/iderudit/025369ar

DOI : https://doi.org/10.7202/025369ar

Aller au sommaire du numéro

Éditeur(s)

Urgences

ISSN

0226-9554 (imprimé)

1927-3924 (numérique)

Découvrir la revue

Citer ce document

Beausoleil, C. \& Delisle, M. (1987). Octobre : Rock garden. Urgences, (16), 12-13. https://doi.org/10.7202/025369ar

Ce document est protégé par la loi sur le droit d'auteur. L’utilisation des services d'Érudit (y compris la reproduction) est assujettie à sa politique d'utilisation que vous pouvez consulter en ligne.

https://apropos.erudit.org/fr/usagers/politique-dutilisation/
Cet article est diffusé et préservé par Érudit.

Érudit est un consortium interuniversitaire sans but lucratif composé de l’Université de Montréal, l’Université Laval et l’Université du Québec à Montréal. Il a pour mission la promotion et la valorisation de la recherche. https://www.erudit.org/fr/ 


\section{Claude Beausoleil/Michael Delisle OCTOBRE: ROCK GARDEN}

Dans la pluie, c'est une ruine

d'ombres, c'est

un tombeau de fleurs

Qui retient les couleurs

des feuilles tombées.

Les pierres fleurissent encore

collection de titres

où ceux qui ont quitté continuent

de parler

De plus en plus ma bouche

est remplie de cailloux

et les os de mes collègues

ressemblent à des fleurs

Est-ce, un pêle-mêle, un paradis ou Angkor Wat

ou le centre-ville après

dix heures du soir? Ce n'est pas

mort ou vif

humain. Je le longe

dans la pluie, noir. C'est

une montée du chant. 


\section{TRADUIRE, DIT-IL}

Il est faux de dire que la poésie ne se traduit pas. Comme tout texte, le poème a ses règles et ses particularités dont on doit tenir compte dans le rendu final, mais cela n'est pas une fin de non traduire en soi. Ce qui est complexe avec le texte poétique, c'est l'ouverture possible à des variantes plus nombreuses peut-être que pour ce qui est d'une information précise comme on peut en retrouver dans un dépliant automobile, par exemple. Les Russes lisent Rimbaud en russe et les Américains en anglais. S'ils connaissent la langue française, ils peuvent le fréquenter dans sa langue d'origine. Pour moi, il n'y a pas de tabou à entretenir sur les méfaits de la traduction. Cet exercice existe pour faire circuler les textes et leurs idées. Rimbaud n'est Rimbaud que lorsqu'il est Rimbaud, c'est-à-dire texte poétique. Les versions en d'autres langues sont des voies d'accès le plus exactes possible, rendant compte de la richesse du texte rimbaldien. Est-il préférable, si on ne lit pas le français, de ne pas lire Rimbaud plutôt que de le lire dans une autre langue (celle du lecteur étranger, éventuel)? Je crois la réponse évidente. Lire Rimbaud dans toutes les langues! Son texte de toute manière demeure étranger, puisque poétique. 